\title{
Bee Venom and Hesperidin Effectively Mitigate Complete Freund's Adjuvant-Induced Arthritis Via Immunomodulation and Enhancement of Antioxidant Defense System
}

\author{
Osama AHMED, ${ }^{1}$ Hanaa FAHIM, ${ }^{1}$ Ayman MAHMOUD, ${ }^{1,2}$ Eman AHMED ${ }^{1}$ \\ ${ }^{1}$ Division of Physiology, Department of Zoology, Faculty of Science, Beni-Suef University, Beni-Suef, Egypt \\ ${ }^{2}$ Department of Endocrinology, Diabetes and Nutrition, Charité Universitätsmedizin Berlin, Berlin, Germany
}

\begin{abstract}
Objectives: This study aims to assess the antirheumatic activity of bee venom (BV) and/or hesperidin as natural products in complete Freund's adjuvant (CFA)-induced arthritis in male Wistar rats.

Material and methods: Rheumatoid arthritis (RA) was induced in 30 male Wistar rats (weight $130 \mathrm{~g}$ to $150 \mathrm{~g}$; age 10 to 12 weeks) by subcutaneous injection of CFA into the right hind paw of the rats. The rats were divided into five groups of six rats in each and administered the following regimens for 21 days: Normal group (given the equivalent volume of saline and carboxymethylcellulose), arthritic group (given the equivalent volume of saline and carboxymethylcellulose), arthritic group treated with BV (treated with BV along with carboxymethylcellulose), arthritic group treated with hesperidin (treated with hesperidin along with saline), and arthritic group treated with BV and hesperidin (treated with BV and hesperidin concurrently).

Results: Bee venom and/or hesperidin successfully reversed the CFA-arthritis-induced increases in right hind leg paw swelling, leukocytes' count, liver lipid peroxidation, serum inflammatory cytokine interleukin (IL-2 and IL-12) levels and spleen tumor necrosis factor-alpha messenger ribonucleic acid (mRNA) expression. Moreover, the CFA-induced down-regulation in serum IL-10 level and spleen IL-4 mRNA expression as well as the deterioration in the antioxidant defense system were significantly improved as a result of BV and hesperidin administration. Both treatments also markedly counteracted the severe inflammatory changes and leukocytic infiltration in the periarticular tissue of the ankle joints. In addition, $\mathrm{BV}$ and hesperidin obviously amended the lymphoid hyperplasia in white pulps of spleen as well as the widening of the medulla and mononuclear cell infiltration found in thymus.

Conclusion: Bee venom and hesperidin administration produced their ameliorative effects on RA via their antioxidant, antiinflammatory and immunomodulatory potentials. BV plus hesperidin particularly seemed to be the most potent in improving RA in Wistar rats.

Keywords: Bee venom; hesperidin; inflammation; oxidative stress; rheumatoid arthritis.
\end{abstract}

Rheumatoid arthritis (RA) is characterized by inflammatory cell infiltration and proliferation of synovial tissue, accompanied by periarticular cartilage and bone destruction. ${ }^{1-3}$ RA incidence rate is approximately 0.5 to $1 \%$ of the general population in the world and three times more frequent in females than males. ${ }^{4-6}$ It was believed that the immunological events in association with genetic factors are thought to be the basis of RA developing. ${ }^{7}$ The complex interaction of various immune modulators (cytokines and effector cells) is responsible for the joint damage that begins at the synovial membrane and covers most intraarticular structures. ${ }^{8}$ The activated inflammatory cells such as macrophages, T-cells and B-cells activate or cause the release of other cells' degradative enzymes, tumor necrosis factoralpha (TNF- $\alpha$ ), antibodies and free radicals, which in turn can be directed against the antigens in the joint, therefore contributing to the progression of the disease, and leading to periarticular tissue degradation and joint deformation. ${ }^{9}$ 
Several experimental models have been developed in rats to study the pathogenesis of the disease and to assess the potential usefulness of antirheumatic drugs. ${ }^{10}$ Rat adjuvant arthritis (AA) is an experimental model of polyarthritis which has been widely used for preclinical testing of numerous antiarthritic agents. ${ }^{11}$ The hallmarks of this model are reliable onset and progression of robust and easily measureable polyarticular inflammation and periarticular cartilage and bone destruction. ${ }^{12,13}$

Currently available drugs or conventional drugs including non-steroidal antiinflammatory drugs, disease-modifying antirheumatic drugs, glucocorticoids (steroids) and biological agents such as TNF- $\alpha$ and interleukin 1 beta (IL-1 $1 \beta$ ) antagonists have shown only limited success against arthritis because of serious side effects. ${ }^{14}$ Accordingly, nowadays, attention of scientists worldwide is directed toward natural products and medicinal plants in the treatment and prevention of diseases due to lower toxicity and fewer side effects. ${ }^{3,15}$

Bee venom (BV) obtained from Apis mellifera, known to contain several pharmacologically active substances, has been believed since ancient times to have beneficial effects in certain arthritic and rheumatoid conditions and is fairly widely used in many countries. ${ }^{16}$ Several studies on the effect of $\mathrm{BV}$ on experimental inflammation were published recently and showed that $\mathrm{BV}$ has a suppressive effect on adjuvant-induced polyarthritis. ${ }^{17}$

Hesperidin, a naturally occurring flavonoid presents in citrus fruits and vegetables, has been reported to exert a wide range of pharmacological effects including antiinflammatory, immunomodulatory, antioxidant and apoptotic effects and could prevent the onset and progression of AA. ${ }^{18}$

Therefore, in this study, we aimed to assess the antirheumatic activity of $\mathrm{BV}$ and/or hesperidin as natural products in complete Freund's adjuvant (CFA)-induced arthritis in male Wistar rats.

\section{MATERIAL AND METHODS}

The study was conducted at Faculty of Science, Beni-Suef University, Egypt between January 2015 and January 2016 and included 30 male Wistar rats (weight $130 \mathrm{~g}$ to $150 \mathrm{~g}$; age 10 to 12 weeks) that were obtained from the National Institute of Ophthalmology, Giza, Egypt. Rats were housed in standard polypropylene cages and maintained under controlled room temperature $\left(22 \pm 2^{\circ} \mathrm{C}\right)$ and humidity $(55 \pm 5 \%)$ with 12 -hour light and 12 -hour dark cycle. They were fed rat chow diet and given drinking water ad libitum. The animals used in the present study were maintained in accordance with the principles and guidelines of the Canadian council on Animal care ${ }^{19}$ and local Experimental Animal Ethics Committee, Faculty of Science, Beni-Suef University, Egypt. All efforts were done to reduce the number of animals to the minimum and to decrease the suffering of animals.

Arthritis was induced by a single subcutaneous injection of $0.1 \mathrm{~mL}$ CFA, a suspension of heatkilled Mycobacterium tuberculosis in mineral oil, into a footpad of the right hind leg paw of male rats. ${ }^{20}$ CFA was obtained from Sigma Chemical Company (Sigma Chemical Co., St Louis, Mo., USA).

Crystalline BV (whole venom of Apis millifera) was obtained as a gift from the Holding Company for Biological Products and Vaccines (Vacsera), Giza, Egypt. It was stored in deep freezer at $-30^{\circ} \mathrm{C}$. BV solution was prepared fresh weekly and injected subcutaneously into the plantar surface of the right hind leg paw. It was dissolved in $0.5 \mathrm{~mL}$ of normal saline solution (sodium chloride, 0.9\%) as a vehicle at dose level of $1 \mathrm{mg} / \mathrm{kg}$ body weight (b.w. $)^{17}$ daily for a period of three weeks.

Hesperidin, purchased from Sigma Chemical Company (Sigma Chemical Co., St Louis, Mo., USA) was dissolved in $1 \%$ carboxymethylcellulose (CMC) as a vehicle, at concentration of $0.5 \%$ $(25 \mathrm{mg} / 5 \mathrm{~mL})$ and given orally at dose level of $25 \mathrm{mg} / \mathrm{kg}$ b.w. ${ }^{21,22}$ by oral gavage daily for three weeks.

The rats were divided into five groups of six rats in each, designated as follows: (i) normal group (normal): rats within this group were given the equivalent volume of the vehicles, saline and $\mathrm{CMC}$. Saline was injected subcutaneously into the plantar surface of the right hind leg paw based on the body weight $(0.5 \mathrm{~mL} / \mathrm{kg}$ b.w.) while $1 \%$ $\mathrm{CMC}$ was given by oral gavage in a volume of $5 \mathrm{~mL} / \mathrm{kg}$ b.w/day for 21 days; (ii) arthritic group (arthritic): this group consisted of arthritic rats that were given the equivalent volume of the vehicles, saline and $\mathrm{CMC}$, like the normal control group 
for 21 days; (iii) arthritic group treated with BV (arthritic+BV): arthritic rats of this group were daily treated with BV (1 mg/kg b.w.) that was injected subcutaneously into the plantar surface of the right hind leg paw, along with $\mathrm{CMC}$ as vehicle by oral gavage daily for 21 days; (iv) arthritic group treated with hesperidin (arthritic+hesperidin): arthritic rats of this group were daily treated with hesperidin ( $25 \mathrm{mg} / \mathrm{kg}$ b.w.) by oral gavage for 21 days, along with saline subcutaneous injection into the plantar surface of the right hind leg paw; and $(v)$ arthritic group treated with BV and hesperidin (arthritic+BV+hesperidin): arthritic rats of this group were daily treated with $\mathrm{BV}$ and hesperidin concurrently for 21 days in the same way as in the previous groups.

The right leg paw circumference just above tarsal pad, an indicator of swelling rate and paw edema, was measured in different groups by wrapping string around that region. The length of the string was measured with a ruler. The measurements were taken every week (on the $7^{\text {th }}$, $14^{\text {th }}$ and $21^{\text {th }}$ days) after adjuvant injection.

At the end of experiment (21 days), blood samples were collected from jugular vein under mild diethyl ether anesthesia. Part of blood from each rat was collected in tubes containing ethylenediaminetetraacetic acid (EDTA) solution ( $50 \mu \mathrm{L}$ of $15 \%$ EDTA/2.5 mL blood) for counting leukocytes. Other part of blood was collected in tubes containing no anticoagulant and left to coagulate, then centrifuged at $3000 \mathrm{rpm}$ for 15 minutes. The clear non-hemolyzed supernatant sera were quickly removed, divided into three portions for each individual animal, and kept at $-30^{\circ} \mathrm{C}$ till used. Spleen, thymus and hind leg ankle region and paw were removed and fixed in 10\% neutral buffered formalin for histopathological examination.

Total leukocyte count (TLC) was carried out by Neubauer chamber using gentian violet. ${ }^{23}$ Differential leukocyte count (DLC) was performed using Giemsa stain. ${ }^{24}$

Lipid peroxidation (LPO) detected as malondialdehyde (MDA) level and glutathione (GSH) content in liver were determined according the methods of Preuss et al. ${ }^{25}$ and Beutler et al., ${ }^{26}$ respectively. The antioxidant enzymes including superoxide dismutase (SOD), glutathione peroxidase (GPx) and glutathione-S-transferase (GST) activities in liver were determined according to assay methods of Marklund and Marklund, ${ }^{27}$ Matkovics et al. ${ }^{28}$ and Mannervik and Gutenberg, ${ }^{29}$ respectively.

Serum IL-2, IL-12 and IL-10 levels of normal control, arthritic control and arthritic treated rats were determined using specific enzyme-linked immunosorbent assay kits purchased from $R \& D$ Systems (R\&D Systems, Inc., Minneapolis, MN, USA) according to manufacturer's instructions.

Total ribonucleic acid (RNA) was isolated from spleen using the RNeasy Mini Kit (Qiagen $\mathrm{GmbH}$, Hilden, Germany), according to the manufacturer protocol. In brief, frozen spleen (approximately $30 \mathrm{mg}$ ) is disrupted in lysis buffer and homogenized. Ethanol is then added to the lysate, creating conditions that promote selective binding of RNA to the RNeasy membrane. The sample is then applied to the RNeasy Mini spin

\begin{tabular}{|c|c|c|}
\hline Target Gene & Gene bank accession number & Primers \\
\hline TNF- $\alpha$ & NM 012675.3 & $\begin{array}{l}\text { Forward: } \\
\text { 5-GACCCTCACACTCAGATCATCTTCT-3' } \\
\text { Reverse: } \\
\text { 5-TGCTACGACGTGGGCTACG-3' }\end{array}$ \\
\hline IL-4 & NM201270.1 & $\begin{array}{l}\text { Forward: } \\
\text { 5-GGTCTCAGCCCCCACCTTGC-3' } \\
\text { Reverse: } \\
\text { 5-CCGTGGTGTTCCTTGTTGCCGT-3' }\end{array}$ \\
\hline GAPDH (Housekeeping gene) & NM 017008.3 & $\begin{array}{l}\text { Forward: } \\
\text { 5-ATGATTCTACCCACGGCAAG-3' } \\
\text { Reverse: } \\
\text { 5-CTGGAAGATGGTGATGGGTT-3' }\end{array}$ \\
\hline
\end{tabular}




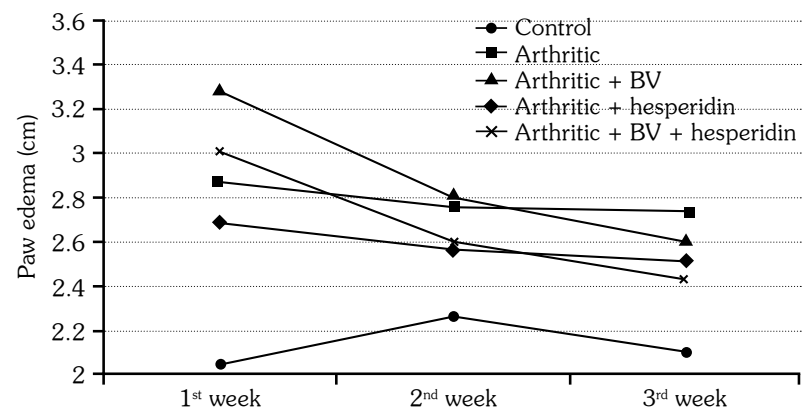

Figure 1. Effect of bee venom and/or hesperidin administration on right leg paw circumference of complete Freund's adjuvant-induced arthritic rats. BV: Bee venom.

column. Total RNA binds to the membrane, contaminants are efficiently washed away, and high-quality RNA is eluted in RNase-free water. The concentration and purity of RNA were determined by ultraviolet spectrophotometer. The concentration was determined from spectrophotometric optical density measurement at wavelengths of 260 and $280 \mathrm{~nm}$. For each tested sample, the ratio between the spectrophotometric readings at $260 \mathrm{~nm}$ and $280 \mathrm{~nm}$ (OD260/OD280) was used to provide an estimate of the purity of RNA, and the ratio in all samples ranged between 1.7 and 2.0 .

Reverse transcriptase reactions were then carried out using high-capacity complementary deoxyribonucleic acid (DNA) reverse transcription kits (AB Applied Biosystems, Foster City, CA, USA). $10 \mu \mathrm{L}$ of RNA sample was added to $10 \mu \mathrm{L}$ of $2 \times$ real-time (RT) master mix that consists of $2 \mu \mathrm{L} 10 \times \mathrm{RT}$ buffer, $0.8 \mu \mathrm{L} 25 \times$ deoxynucleotide mix $(100 \mathrm{mM}), 10 \times \mathrm{RT}$ random primers, $2 \mu \mathrm{L}$ $10 \times \mathrm{RT}$ random primers, $1 \mu \mathrm{L}$ MultiScribe ${ }^{\mathrm{TM}}$
Table 2. Effect of bee venom and/or hesperidin administration on total leukocyte count of complete Freund's adjuvant-induced arthritic rats

\begin{tabular}{lccc}
\hline Groups & $\begin{array}{c}\text { TLC } \\
\left(\text { cell } \times 10^{3} / \mathrm{mm}^{3}\right)\end{array}$ & Change \\
\cline { 2 - 2 } & Mean $\pm S D$ & & $\%$ \\
\hline Normal & $4.10 \pm 0.10^{\mathrm{b}}$ & - \\
Arthritic & $7.75 \pm 1.00^{\mathrm{a}}$ & & 89.02 \\
Arthritic + BV & $5.12 \pm 0.96^{\mathrm{b}}$ & & -33.98 \\
Arthritic + hesperidin & $4.95 \pm 0.48^{\mathrm{b}}$ & -36.13 \\
Arthritic + BV + hesperidin & $4.12 \pm 0.53^{\mathrm{b}}$ & -46.88 \\
\hline
\end{tabular}

TLC: Total leukocyte count; SD: Standard deviation; Number of animals in each group is six. Values, which have the same superscript symbol(s), are not significantly different. Percentage (\%) changes were calculated by comparing arthritic control group with normal control and arthritic-treated groups with the arthritic control group.

Reverse Transcriptase and $4.2 \mu \mathrm{L}$ nucleasefree water. Reverse transcriptase reactions were carried out in a DNA thermal cycler at $25^{\circ} \mathrm{C}$ for 10 minutes, $37^{\circ} \mathrm{C}$ for 120 minutes and $85^{\circ} \mathrm{C}$ for five minutes. The complementary DNA was then stored at $-20^{\circ} \mathrm{C}$ until used for RT polymerase chain reaction (PCR) analysis.

Real-time PCR was performed using $2 \mu \mathrm{L}$ template in a $20 \mu \mathrm{L}$ reaction containing $0.25 \mu \mathrm{M}$ of each primer and $12.5 \mu \mathrm{L}$ SYBR Green RT-PCR MasterMix (Qiagen $\mathrm{GmbH}$, Hilden, Germany). Each run consisted of $50^{\circ} \mathrm{C}$ for two minutes and $95^{\circ} \mathrm{C}$ for 20 minutes followed by 45 cycles of $94^{\circ} \mathrm{C}$ for 15 seconds, $60^{\circ} \mathrm{C}$ for 20 seconds, and $72^{\circ} \mathrm{C}$ for 30 seconds in a RT quantitative PCR machine. Three samples were tested for each group. The values were normalized against the housekeeping gene glyceraldehyde-3-phosphate dehydrogenase (GAPDH).

The gene sequences of forward and reverse primers of IL- 4 and TNF- $\alpha$ and GAPDH ${ }^{30}$ were

Table 3. Effect of bee venom and/or hesperidin administration on differential leukocyte count of complete Freund's adjuvant-induced arthritic rats

\begin{tabular}{|c|c|c|c|c|c|c|c|c|c|}
\hline & $\begin{array}{l}\text { Lymphocyte } \\
\left.\text { (cell } / \mathrm{mm}^{3}\right)\end{array}$ & Change & $\begin{array}{l}\text { Monocyte } \\
\left.\text { (cell//mm } \mathrm{mm}^{3}\right)\end{array}$ & Change & $\begin{array}{l}\text { Neutrophil } \\
\text { (cell//mm }{ }^{3} \text { ) }\end{array}$ & Change & $\begin{array}{l}\text { Eosinophil } \\
\left(\text { cell } / \mathrm{mm}^{3} \text { ) }\right.\end{array}$ & Change & $\begin{array}{l}\text { Basophile } \\
\left.\text { (cell/mm } / \mathrm{mm}^{3}\right)\end{array}$ \\
\hline Groups & Mean \pm SD & $\%$ & Mean \pm SD & $\%$ & $\overline{\text { Mean } \pm S D}$ & $\%$ & $\overline{M e a n} \pm S D$ & $\%$ & Mean \pm SD \\
\hline Normal & $2446 \pm 72^{\mathrm{d}}$ & - & $164 \pm 24^{c}$ & - & $1216 \pm 201^{\mathrm{a}}$ & - & $68 \pm 14^{\mathrm{a}}$ & - & $00 \pm 00$ \\
\hline arthritic & $5632 \pm 144^{a}$ & 130.22 & $801 \pm 170^{a}$ & 388.41 & $1214 \pm 144^{a}$ & -0.16 & $104 \pm 26^{a}$ & 51.71 & $00 \pm 00$ \\
\hline Arthritic + BV & $3874 \pm 95^{b}$ & -31.21 & $512 \pm 59^{\mathrm{ab}}$ & -36.08 & $683 \pm 62^{b}$ & -43.78 & $68 \pm 17^{a}$ & -34.41 & $00 \pm 00$ \\
\hline Arthritic + hesperidin & $3911 \pm 86^{b}$ & -30.56 & $462 \pm 119 b^{c}$ & -42.32 & $528 \pm 17^{b}$ & -56.49 & $50 \pm 29^{a}$ & -52.09 & $00 \pm 00$ \\
\hline Arthritic $+\mathrm{BV}+$ hesperidin & $3145 \pm 99^{c}$ & -44.16 & $275 \pm 55 b^{c}$ & -65.67 & $659 \pm 63^{b}$ & -47.98 & $41 \pm 24^{a}$ & -60.58 & $00 \pm 00$ \\
\hline
\end{tabular}

BV: Bee venom; SD: Standard deviation; Number of animals in each group is six. Values, which have the same superscript symbol(s), are not significantly different. Percentage (\%) changes were calculated by comparing arthritic control group with normal control and arthritic-treated groups with the arthritic control group. 
shown in Table 1. All the molecular analyses have been carried out at Molecular Biology Laboratory, CliniLab, Cairo, Egypt.

After sacrifice and dissection, spleen, thymus and hind leg paws and ankle regions were removed and washed in saline. Pieces from spleen and thymus were fixed in 10\% neutral buffered formalin. The hind leg paws and ankle regions were decalcified for 10 days with ethylenediaminetetraaceticacid, and then were fixed in $10 \%$ neutral buffered formalin. The fixed tissues were transferred to Pathology Department, National Cancer Institute, Cairo University, Egypt, for processing, blocking in paraffin wax, sectioning and staining with hematoxylin and eosin. The stained sections were examined by expert histopathologists.

\section{Statistical analysis}

Results were expressed as mean \pm standard error. The data were analyzed by one-way analysis of variance using PC-STAT, University of Georgia, followed by least significant difference analysis to discern the main effects and compare various groups with each other. ${ }^{31}$ Values of $\mathrm{p}<0.05$ were considered statistically significant.

\section{RESULTS}

In the present study, the right hind leg paw circumference was used as an indicator of the swelling rate and paw edema. The administration of CFA to Wistar rats resulted in a significant $(p<0.05)$ increase in paw swelling when compared to normal control group at the first, second and third weeks with percentage increases of 40.1, 22.4 , and $28.7 \%$, respectively. The treatment of arthritic rats with BV induced a non-significant increase $(p>0.05)$ at the first week of CFA injection while the treatment with hesperidin and BV plus hesperidin produced a significant decrease $(p<0.05)$. At the third week, the treatment of the arthritic rats with $\mathrm{BV}$ and/or hesperidin produced a significant decrease of the elevated values of paw edema represented by the right hind leg paw circumference in comparison to the arthritic control animals (Figure 1).

The TLC and DLC of the arthritic control rats exhibited significant $(p<0.05)$ leukocytosis with a significant increase in lymphocyte and monocyte

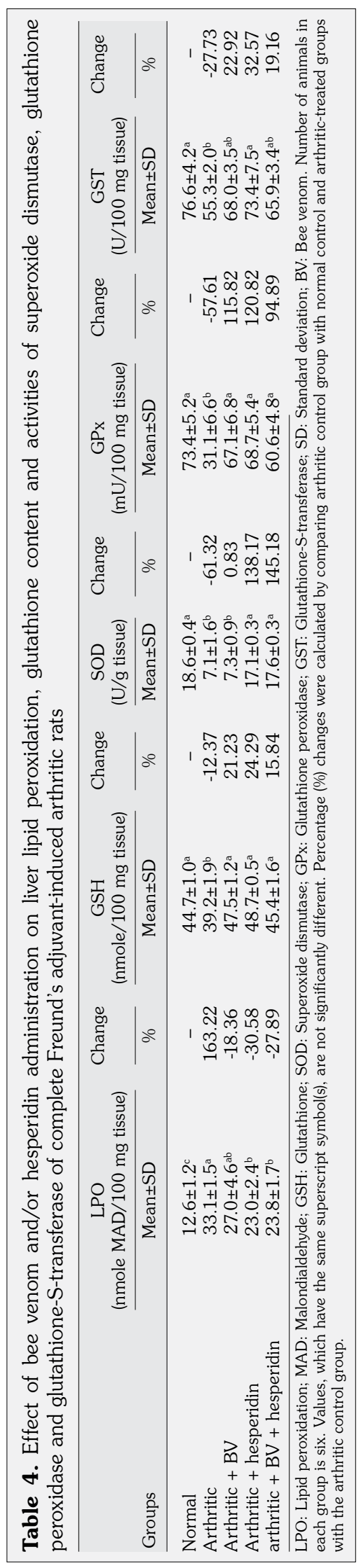


Table 5. Effect of bee venom and/or hesperidin administration on serum interleukin-2, interleukin-12 and interleukin-10 cytokine levels of complete Freund's adjuvant-induced arthritic rats

\begin{tabular}{|c|c|c|c|c|c|c|}
\hline & IL-2 (pg/mL) & Change & IL-12 (pg/mL) & Change & IL-10 (pg/mL) & Change \\
\hline & Mean \pm SD & $\%$ & Mean \pm SD & $\%$ & Mean \pm SD & $\%$ \\
\hline Normal & $32.5 \pm 2.0^{c}$ & - & $20.4 \pm 0.5^{c}$ & - & $117.0 \pm 15.3^{a}$ & - \\
\hline Arthritic & $126.7 \pm 18.7^{\mathrm{a}}$ & 290.21 & $323.3 \pm 51.9^{a}$ & 1482.34 & $50.4 \pm 10.7^{b}$ & -56.91 \\
\hline Arthritic + BV & $65.2 \pm 7.9^{\mathrm{b}}$ & -48.56 & $132.1 \pm 18.0^{\mathrm{b}}$ & -59.14 & $62.9 \pm 4.8^{\mathrm{b}}$ & 24.75 \\
\hline Arthritic + hesperidin & $76.8 \pm 8.2^{\mathrm{b}}$ & -39.42 & $109.9 \pm 25.7^{b}$ & -66.02 & $90.9 \pm 4.4^{\mathrm{a}}$ & 80.44 \\
\hline Arthritic $+\mathrm{BV}+$ hesperidin & $71.1 \pm 6.9^{b}$ & -43.90 & $82.3 \pm 8.1^{\mathrm{bc}}$ & -74.55 & $92.9 \pm 8.1^{\mathrm{a}}$ & 84.29 \\
\hline
\end{tabular}

IL: Interleukin; SD: Standard deviation; BV: Bee venom. Number of animals in each group is six.Values, which have the same superscript symbol(s), are not significantly different. Percentage (\%) changes were calculated by comparing arthritic control group with normal control and arthritic-treated groups with the arthritic control group.

count $(130.2 \%$ and $388.4 \%$, respectively) when compared with the normal control group. As a result of the $\mathrm{BV}$ and/or hesperidin treatments, the leukocytosis as well as the lymphocyte, monocyte, neutrophil and eosinophil counts declined remarkably in comparison with the arthritic control group (Tables 2 and 3).

The effect of BV and/or hesperidin treatments on liver oxidative stress and antioxidant defense system were shown in Table 4. As a result of CFA injection, LPO was increased threefold $(163.2 \%)$ in arthritic control group than normal control group. The treatment of arthritic rats with hesperidin and $\mathrm{BV}$ plus hesperidin decreased significantly $(p<0.05)$ the elevated lipid peroxidation while the BV supplementation alone produced non-significant $(p>0.05)$ change. The arthritic control rats showed a significant $(p<0.05)$ decline in liver GSH $(-12.4 \%)$, SOD

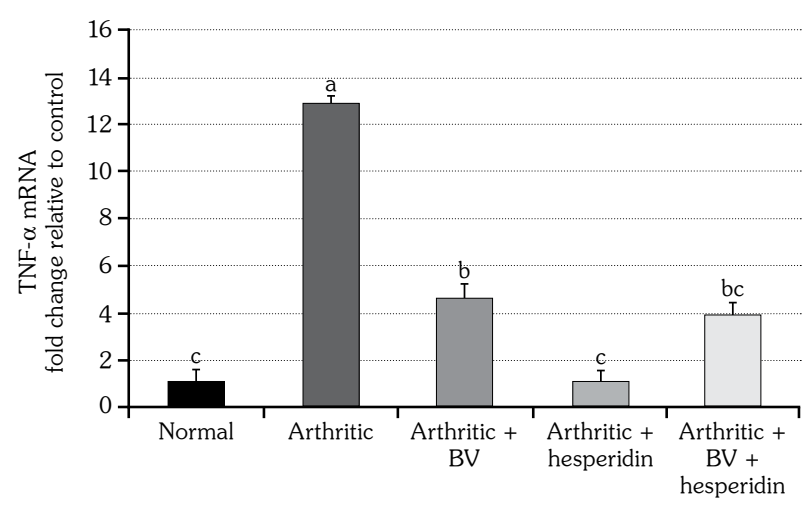

Figure 2. Effect of bee venom and/or hesperidin treatments on tumor necrosis-alpha messenger ribonucleic acid expression level in spleen tissue of complete Freund's adjuvant-induced arthritic rats. Three replicates were used for each group. Means, which share same symbol(s), are not significantly different. TNF- $\alpha$ : Tumor necrosis factor-alpha; mRNA: Messenger ribonucleic acid; BV: Bee venom.
(-61.3\%), GPx (-57.6\%) and GST (-27.6\%) activities when compared to the normal control rats. As a result of hesperidin treatment, all of the tested antioxidant parameters were significantly $(p<0.05)$ improved. Also, BV plus hesperidin significantly enhanced GSH, SOD, GPx, while the GST activity was non-significantly affected. On the other hand, the treatment with $\mathrm{BV}$ significantly increased GSH and GPx while SOD and GST were non-significantly increased ( $p>0.05$ ).

The administration of CFA to Wistar rats produced a significant $(p<0.05)$ increase in serum IL-2 (290.2\%) and IL-12 (1,432.3\%) levels while it induced a significant decrease in serum IL-10 level $(-56.91 \%)$ as compared to normal control rats. The treatment of the arthritic rats with $\mathrm{BV}$ and/or hesperidin caused a significant decrease in serum IL-2 and IL-12 levels as compared to the arthritic

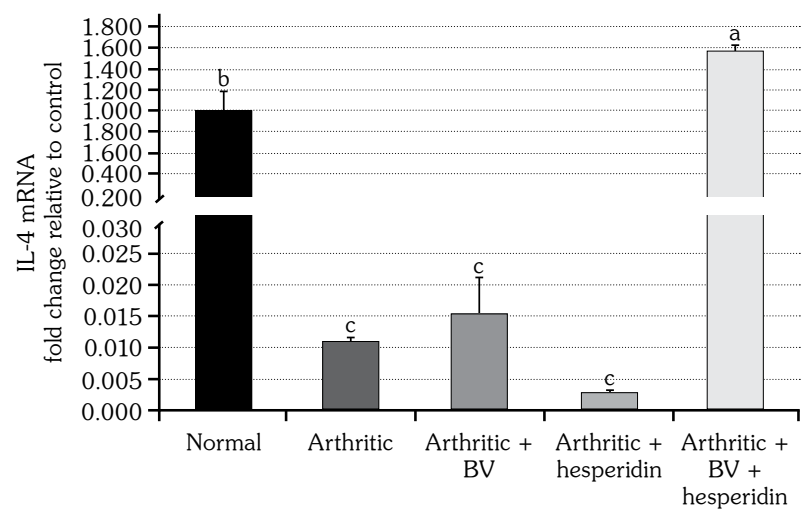

Figure 3. Effect of bee venom and/or hesperidin administration on interleukin-4 messenger ribonucleic acid expression level in spleen tissue of complete Freund's adjuvant-induced arthritic rats. Three replicates were used for each group. Means, which share same symbol(s), are not significantly different. IL-4: Interleukin-4; mRNA: Messenger ribonucleic acid; $\mathrm{BV}$ : Bee venom. 

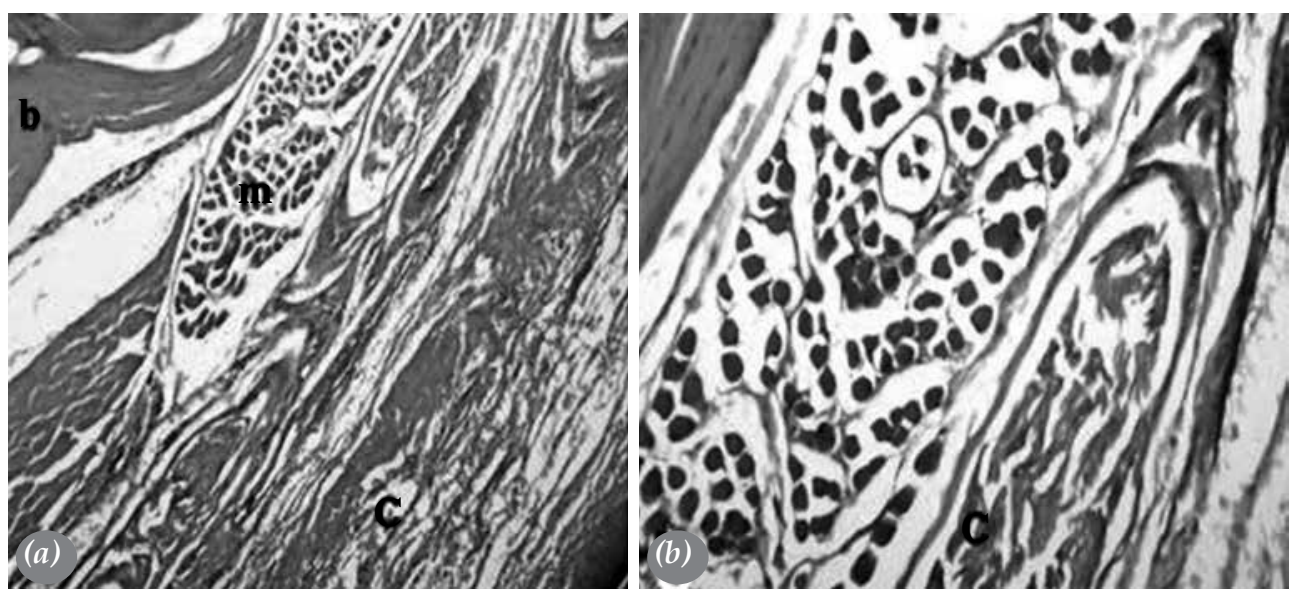

Figure 4. Photomicrographs of right leg ankle joint sections of normal rats. (a) showed normal histological structure of articular fibrous joint capsules (c), bone (b) and skeletal muscle (m) (H-E $\times 160)$. (b) showed magnification of (14a) that identified fibrous joint capsule. (H-E×400).

control. On the other hand, the lowered serum IL-10 level was significantly increased $(p<0.05)$ as a result of hesperidin and BV plus hesperidin treatments while it was non-significantly $(p>0.05)$ changed as a result of the $\mathrm{BV}$ treatment alone (Table 5).

The CFA-induced arthritic control rats exhibited a significant increase in the messenger RNA (mRNA) expression level of TNF- $\alpha$ cytokine while the IL- 4 expression was significantly decreased in the spleen tissue when compared to the normal control rats. The BV treated as well as hesperidin treated rats showed a significant $(p<0.05)$ decrease in the elevated level of TNF- $\alpha$ expression while they exhibited a non-significant ( $p>0.05)$ change in the IL-4 mRNA expression level as compared to the arthritic control group. Additionally, the treatment of the arthritic rats with $\mathrm{BV}$ plus hesperidin resulted in a significant decrease in the TNF- $\alpha$ mRNA expression level and caused a significant increase in the expression level of IL-4 cytokine when compared to the arthritic control rats (Figures 2 and 3).

Histopathological examination of the right hind ankle joint of control rats showed normal histological structure of the joint (bone and fibrous joint capsule) (Figures $4 \mathrm{a}$ and b). On the other hand, CFA-induced arthritic rats had severe inflammatory changes in the fibrous joint capsule ranging from focal leucocytic infiltration (granuloma) to massive diffuse leucocytic infiltration. The most common leucocytes were lymphocytes, macrophages, epithelioid cells and
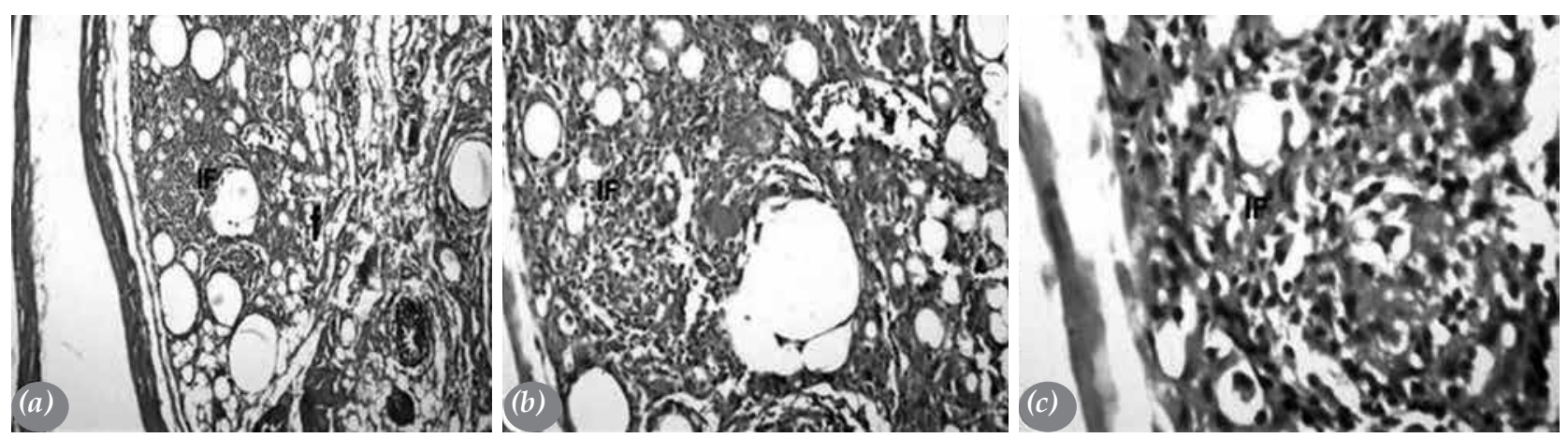

Figure 5. Photomicrographs of right leg ankle joint sections of arthritic rats. (a) showed a very severe form of focal as well as diffuse inflammatory cells infiltration in joint capsule with fat deposition (f) (H-Ex160). (b) showed a magnification of (15a) to identify inflammatory cells infiltration in joint capsule $(\mathrm{H}-\mathrm{E} \times 400)$. (c) showed a magnification of (b) with inflammatory cells infiltration in synovium (H-E×800). IF: Inflammatory cells infiltration. 

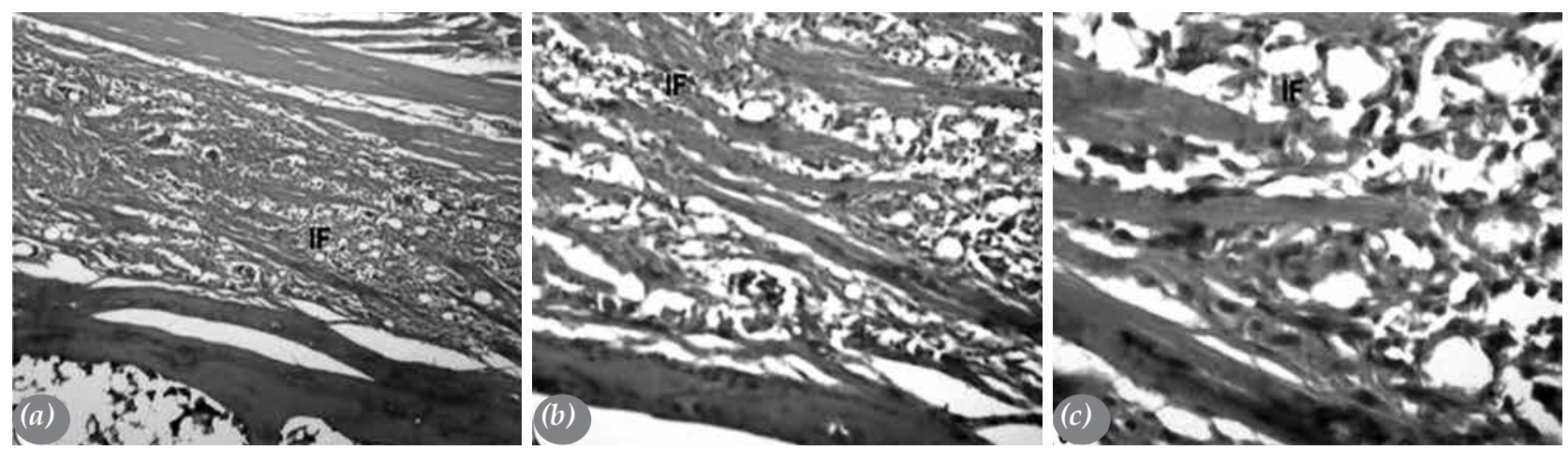

Figure 6. Photomicrographs of right leg ankle joint sections of arthritic rats treated with bee venom. (a) showed a moderate form of inflammatory cells infiltration in joint capsule $(\mathrm{H}-\mathrm{E} \times 160)$. (b) showed magnification of (16a) to identify inflammatory cells infiltration in joint capsule $(\mathrm{H}-\mathrm{E} \times 400)$. (c) showed magnification of (16b) and depicted inflammatory cells infiltration $(\mathrm{H}-\mathrm{E} \times 800)$. IF: Inflammatory cells infiltration.
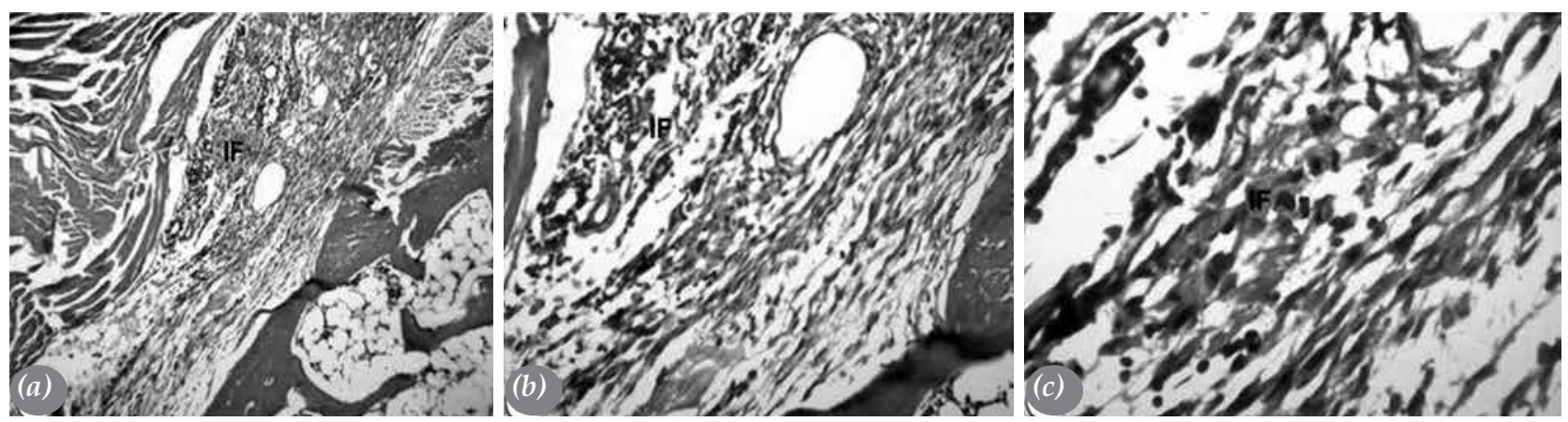

Figure 7. Photomicrographs of right leg ankle joint sections of arthritic rats treated with hesperidin. (a) showed a severe form of inflammatory cells aggregation in joint capsule $(\mathrm{H}-\mathrm{E} \times 160)$. (b) showed magnification of (a) to identify inflammatory cell aggregation in joint capsule $(\mathrm{H}-\mathrm{E} \times 400)$. (c) showed magnification of Figure (b) and depicted inflammatory cells infiltration (H-Ex800). IF: Inflammatory cells infiltration.
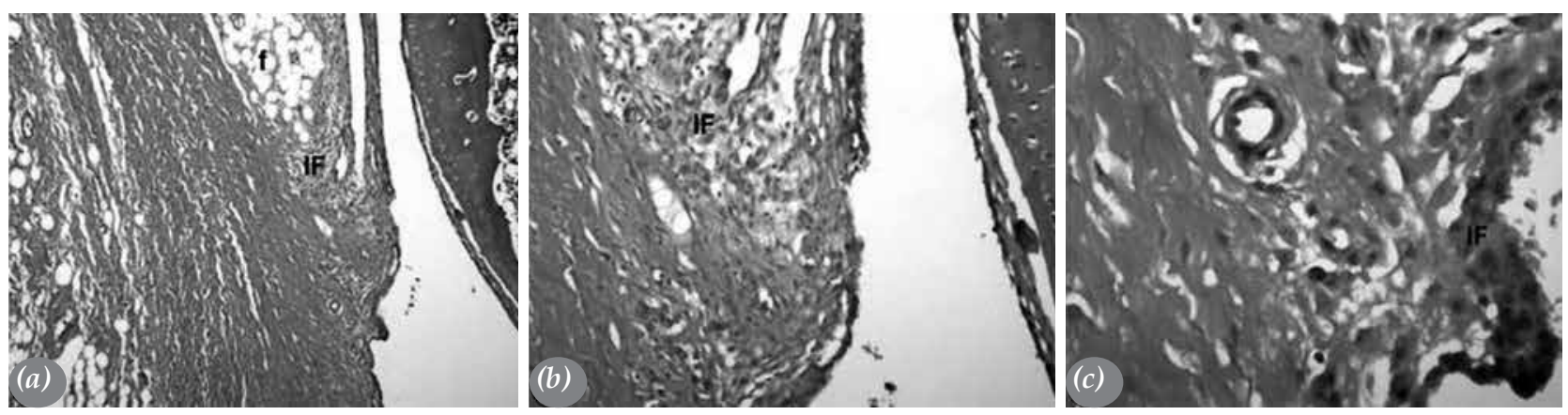

Figure 8. Photomicrographs of right leg ankle joint sections of arthritic rats treated with bee venom plus hesperidin showed a mild form of inflammatory cells infiltration and fat deposition (f) in fibrous articular joint capsule (H-Ex160). (b) showed magnification of (a) to identify few inflammatory cells infiltration in fibrous articular joint capsule (H-Ex400). (c) showed magnification of (b) and depicted inflammatory cells infiltration (H-Ex800). IF: Inflammatory cells infiltration.

giant cells (Figures 5a-c). The arthritic group treated with BV (Figures 6a-c) showed moderate inflammatory changes in the fibrous joint capsule. In hesperidin treated group, the fibrous joint capsule showed a severe form of inflammatory cells aggregation (Figures 7a-c). The arthritic rats treated with BV plus hesperidin showed mild inflammatory reaction (Figures 8a-c).

The spleen sections of control rats exhibited normal histological structure of the lymphoid 


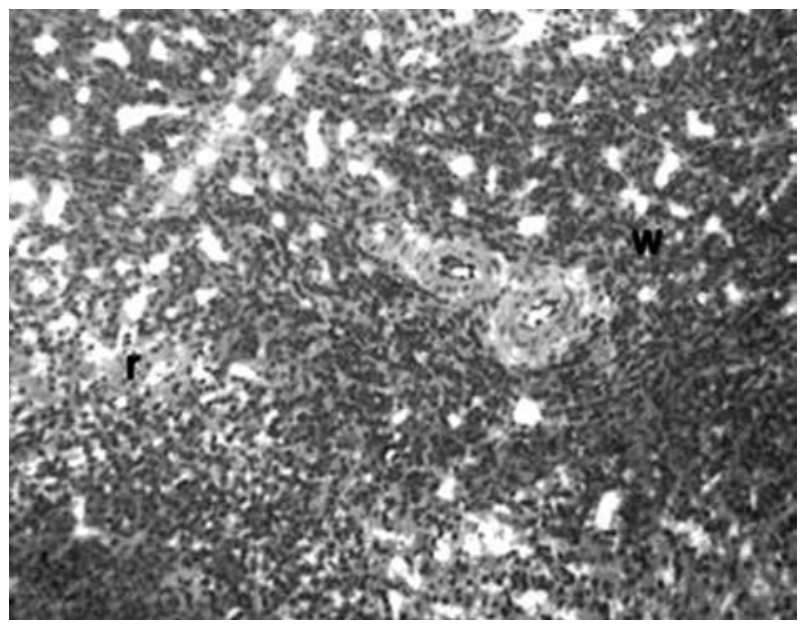

Figure 9. A photomicrograph of spleen section from normal control rat showing normal histological structure of lymphoid follicles in white pulp (w) and surrounding red pulp (r) $(\mathrm{H}-\mathrm{E} \times 400)$.

cells in white pulps as well as the histological structure of the red pulps (Figure 9). The spleen sections of the arthritic animals showed lymphoid hyperplasia in the white pulps (Figure 10). The treatment of the arthritic rats with BV showed no improvement effects on the hyperplasia of the lymphoid cells (Figure 11). On the other hand, hesperidin and BV plus hesperidin treated arthritic rats greatly improved the histopathological impacts (lymphoid hyperplasia) occurring in the white pulps due to CFA-administration (Figures 12 and 13).

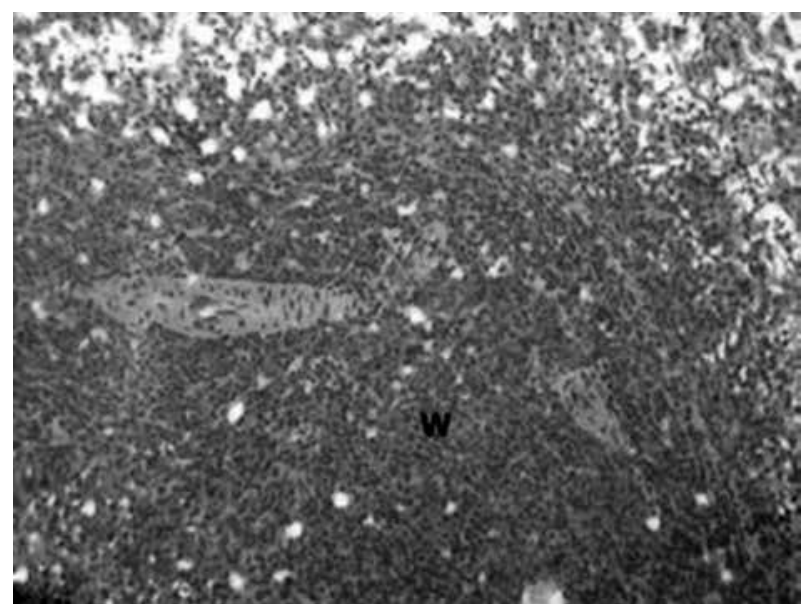

Figure 11. A photomicrograph of spleen section from arthritic rat treated with bee venom showing lymphoid hyperplasia in white pulp (w) $(\mathrm{H}-\mathrm{E} \times 400)$.

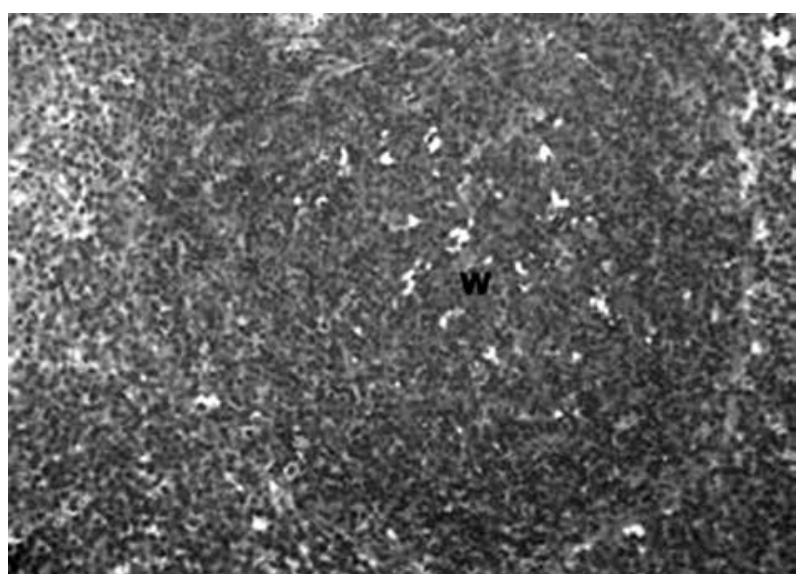

Figure 10. A photomicrograph of spleen section from arthritic rat showing moderate lymphoid hyperplasia in white pulp (w) $(\mathrm{H}-\mathrm{E} \times 400)$.

As indicated in Figure 14, the thymus of control rats depicted normal histological structure of lymphoid cells in both peripheral cortex (c) and central medulla (m). Thymus sections from arthritic rats showed widening of the medulla (Figure 15a) with minimal necrobiotic change (Figure 15b) and congestion of blood vessels and mononuclear cell infiltration in the area surrounding blood vessels (Figure 15c). The BV and $\mathrm{BV}$ plus hesperidin treated rats presented improved histological section near normal histological appearance (Figures 16 and 18, respectively) while, those treated with hesperidin had degenerated lymphocytes in the medulla (Figure 17).

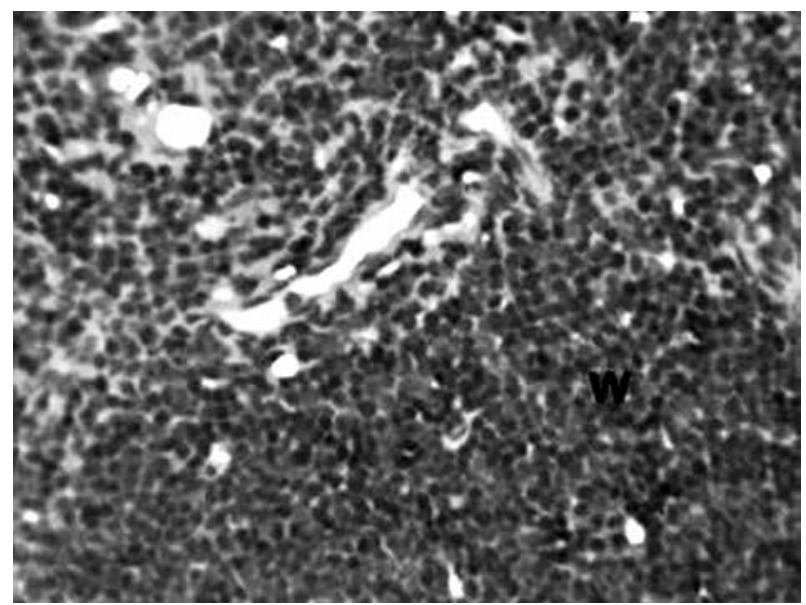

Figure 12. A photomicrograph of spleen section from arthritic rat treated with hesperidin showing no histopathological alteration in white pulp (w) $(\mathrm{H}-\mathrm{E} \times 400)$ 


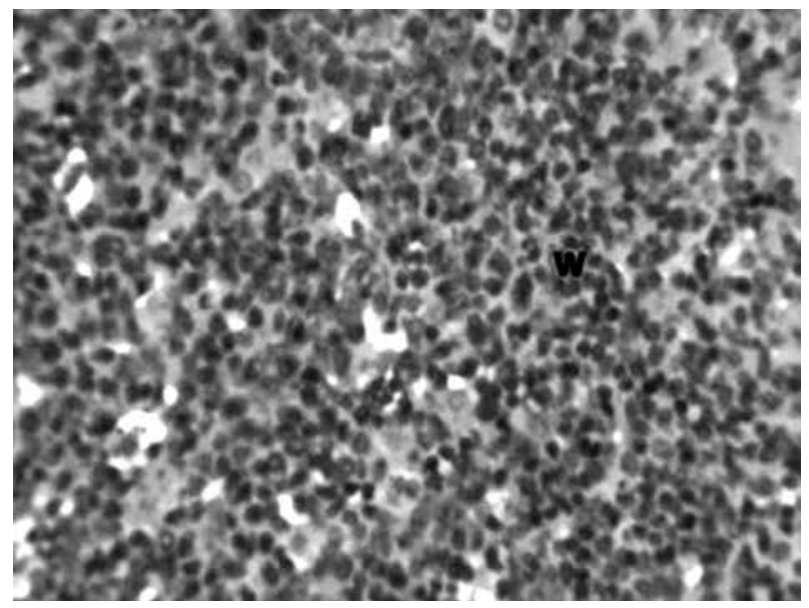

Figure 13. A photomicrograph of spleen section from arthritic rat treated with bee venom plus hesperidin showing no histopathological alterations in white pulps (w) $(\mathrm{H}-\mathrm{E} \times 400)$.

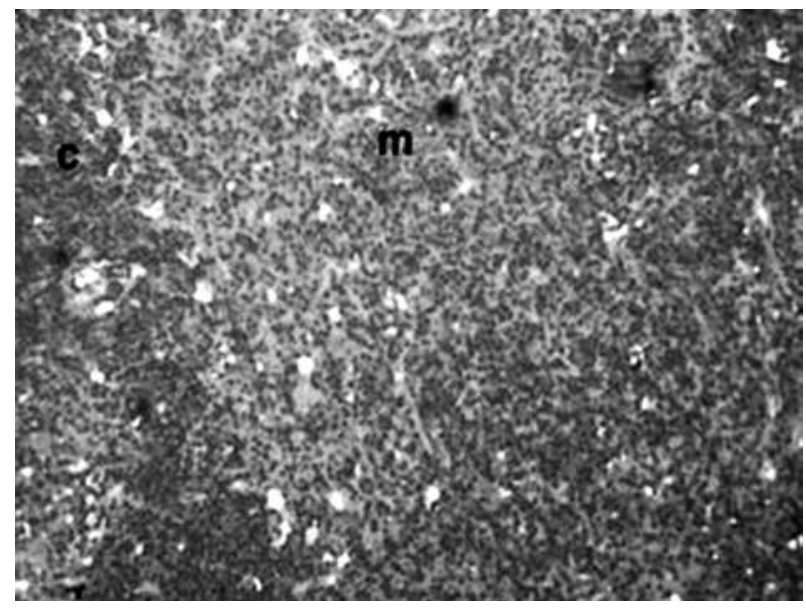

Figure 14. A photomicrograph of thymus section from normal control rat showing normal histological structure of lymphoid cells in both peripheral cortex (c) and central medulla (m) $(\mathrm{H}-\mathrm{E} \times 400)$.
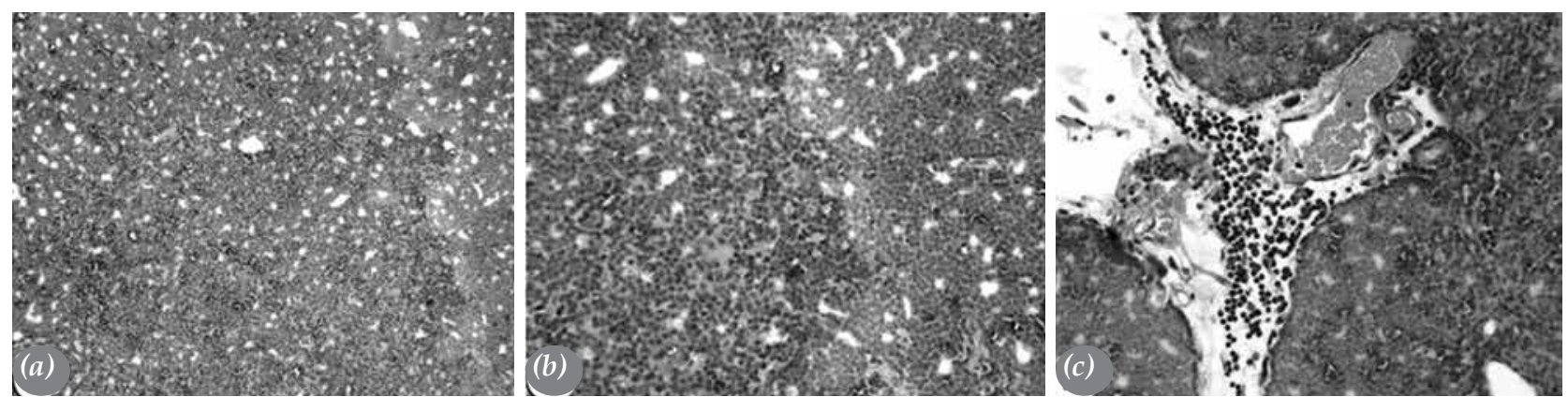

Figure 15. Photomicrographs of thymus sections from arthritic rats. (a) Showed widening of medulla (H-Ex400). (b) Showed minimal necrobiotic changes in medulla $(\mathrm{H}-\mathrm{E} \times 400)$. (c) Showed congestion of blood vessels and mononuclear cell infiltration in area surrounding blood vessels $(\mathrm{H}-\mathrm{E} \times 400)$.

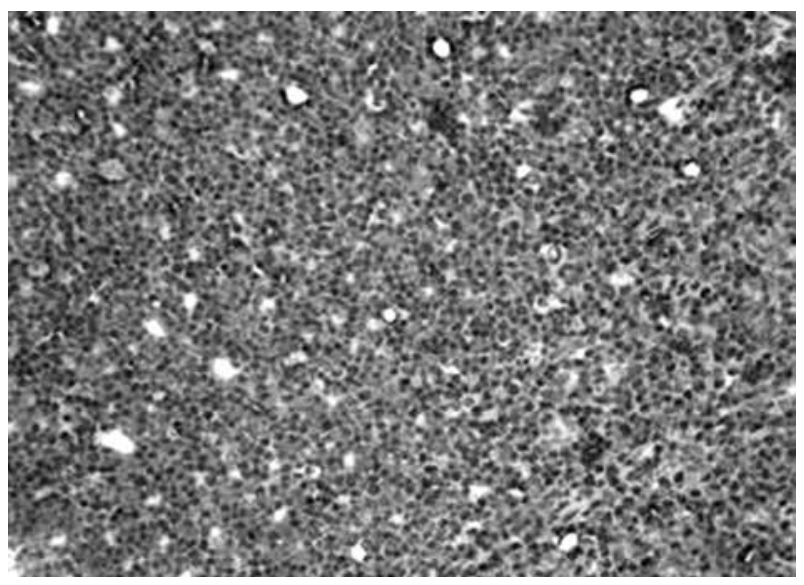

Figure 16. A photomicrograph of thymus section from arthritic rat treated with bee venom showing improved histological section (near normal histological appearance) (H-E×400).

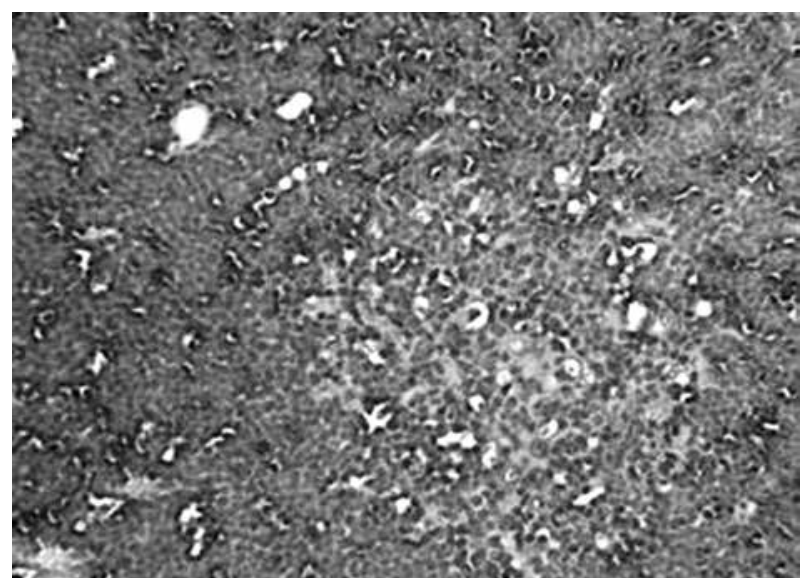

Figure 17. A photomicrograph of thymus section from arthritic rat treated with hesperidin showing mild degenerated changes in lymphocytes within medulla (H-E×400). 


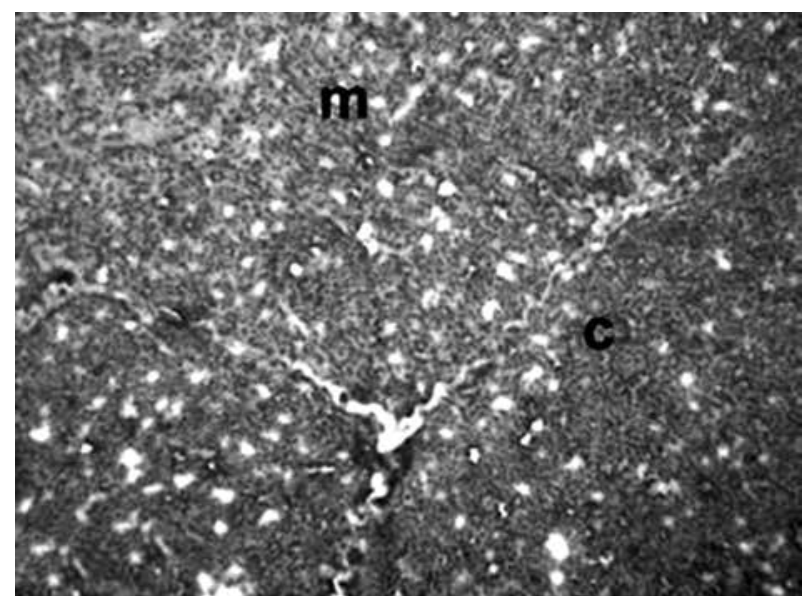

Figure 18. A photomicrograph of thymus section from arthritic rat treated with bee venom plus hesperidin showing normal histological structure of both cortex (c) and medulla (m) $(\mathrm{H}-\mathrm{E} \times 400)$.

\section{DISCUSSION}

Rheumatoid arthritis is a chronic autoimmune disease characterized by joint swelling, synovial membrane inflammation and cartilage destruction. ${ }^{18}$ Rat model of RA induced by CFA has similar characteristics to human RA in the aspects of histology and immunology making it reasonable to screen new drugs for the treatment of RA. ${ }^{32}$ Although conventional drugs are used for the clinical management of $\mathrm{RA}$, the use of these drugs have been associated with limited efficacy, ${ }^{33}$ besides being expensive and causing severe adverse effects. ${ }^{34}$ This has prompted the use of complementary and alternative medicine as safer and more effective methods of treatment. ${ }^{9,35}$ In this study, the antiinflammatory and antiarthritic effects of two natural products, namely, BV and hesperidin were investigated.

A change in paw volume has been classically used for evaluating antiinflammatory effects on RA. ${ }^{36}$ In the present study, the treatment of rats with BV and/or hesperidin significantly inhibited the paw swelling, which suggests the effectiveness of these treatments on treating AA.

The TLC and DLC data showed a profound leukocytosis with higher lymphocyte and monocyte counts in the arthritic control animals. This leukocytosis is possibly due to CFA which is an antigen solution of attenuated Mycobacterium tuberculosis and adjuvant that are used to elicit the immune response by the host animal to this antigen. ${ }^{37}$ Therefore, the count of leukocytes, particularly lymphocytes and monocytes, which are the most prominent cells in the rheumatoid synovium and are important in the pathogenesis of arthritis, may be elevated. ${ }^{38,39}$ These findings are concomitant with the histological results that depicted diffuse inflammatory cells in the joint capsule, lymphoid hyperplasia in the white pulp of spleen and mononuclear leukocytic infiltration in the thymus of CFA-arthritic rats. It was found that the BV and/or hesperidin treatments, produced a marked decrease of the elevated TLC as well as the lymphocyte, monocyte and neutrophil counts, indicating the antiinflammatory effect of the treatments on the AA course.

Concerning oxidative stress and antioxidant defense system, the liver LPO was significantly elevated in CFA-induced arthritic rats while the GSH content and the activities of antioxidant enzymes SOD, GPx and GST were significantly decreased. This elevation in oxidative stress and suppression of antioxidant defense system may be involved in the pathogenic events of RA. This elucidation was evidenced and supported by many previous investigators. As reported by Umar et al., ${ }^{40}$ LPO has been implicated in the pathogenesis of inflammatory arthritis. During LPO, lipid peroxyl radicals are produced, which may lead to cell membrane damage. In the present study, the level of MDA, a stable adduct of LPO, increased obviously in liver of arthritic control rats suggesting that CFA or its metabolites produce free radical species that attack lipid components, leading to lipid peroxidation. ${ }^{41}$ This finding is in accordance with Rasool and Sabina, ${ }^{42}$ who found that the administration of $0.1 \mathrm{~mL}$ CFA into the right hind leg paw of Swiss albino mice increased the liver lipoprotein level expressively. The present results are also in concordance with Ahmed et al., ${ }^{43}$ who reported an increase in lipid peroxides level and decrease in GSH level and GPx, SOD and glutathione reductase (GR) activities in serum of CFA-induced arthritic rats. Treatment of CFA-induced arthritic rats with BV and/or hesperidin induced a marked decrease in the elevated LPO. On the other hand, the declined GSH content and GPx and GST activities, as a result of their consumption during oxidative stress and cellular lysis, ${ }^{44,45}$ are replenished successfully 
by $\mathrm{BV}$, hesperidin and BV plus hesperidin supplementation probably by scavenging free radicals. However, the SOD activity was significantly increased only as a result of treatment of arthritic rats with hesperidin and BV plus hesperidin. These results indicate that the three treatments play an important role in treating the AA course through inhibition of the oxidative stress and enhancement of antioxidant defense system. Hesperidin and BV plus hesperidin had potent effects in reducing the lipid peroxidation and enhancing antioxidant defense system. However, there was no sufficient effect on antioxidant system in the arthritic group treated with $\mathrm{BV}$ alone.

Rheumatoid arthritis is an autoimmune disease characterized by the proliferation of synovium and the infiltration of chronic inflammatory cells. Cytokines from synovium and inflammatory cells, monocytes and lymphocytes, are thought to be important in the initiation and perpetuation of RA. ${ }^{46}$ In the present study, the levels of inflammatory cytokines including IL-2 and IL-12 were significantly increased while the level of antiinflammatory cytokine, IL-10, was decreased in the arthritic rats. These increases in the inflammatory cytokines concentrations may reflect their crucial role in the pathophysiology of arthritis development in animal models and humans. ${ }^{13,43,47}$ IL-12 has been documented to synergize with a variety of cytokines and induce the production of proinflammatory cytokines. ${ }^{48,49}$ Additionally, Lipsky et al. ${ }^{50}$ stated that IL-2 is increased in concentration in a variety of $\mathrm{T}$ cell-mediated inflammatory conditions, such as RA, in which serum IL-2 levels are indicative of disease activity. Moreover, in the CFA-arthritic rats of the current study, the spleen mRNA expression of the proinflammatory cytokine, TNF- $\alpha$, which is one of the key cytokine molecules that cause inflammation in $\mathrm{RA},{ }^{51}$ was markedly increased. Conversely, the spleen mRNA expression of the typical antiinflammatory cytokine, IL-4, was extremely down-regulated in the arthritic control group. This indicates that the induction of CFA in the Wistar rats enhances the inflammatory mediators while suppressing the antiinflammatory cytokines production, thus developing the inflammation process as a result. The treatment of the arthritic rats with BV and hesperidin potentially decreased the elevated proinflammatory and inflammatory mediator (IL-2, IL-12 and TNF- $\alpha$ ) levels. Also, the antiinflammatory cytokines (IL-10 and IL-4) were variably affected by BV and hesperidin supplementation. While serum IL-10 level was markedly increased as a result of treatment of CFA-induced arthritic rats with BV, hesperidin and BV plus hesperidin, IL-4 mRNA expression in spleen tissue was significantly increased only due to treatment with $\mathrm{BV}$ plus hesperidin. Thus, taken these changes together, it can be suggested that the treatments suppress the AA synovium inflammation mainly by inhibiting $\mathrm{T}$ helper (Th) 1 cells differentiation and activating Th2 cells differentiation, thus inhibiting the production of proinflammatory cytokines and activating the production of antiinflammatory interleukins. Moreover, the BV plus hesperidin supplementation seems to be the most potent in reducing the triggered inflammation. This is most likely due to its most powerful effect on both inhibiting the Th1 cells that produce and stimulate the production of TNF- $\alpha$, IL-2 and IL-12 and promoting Th2 cells, which up-regulate the expression of IL-10 and IL-4.

Histopathologically, the former results of the immunological indices were supported by the histopathological examination of the ankle joint sections. The BV and/or hesperidin treated arthritic rats showed an obvious reduction in the extent of inflammatory cells infiltration in the fibrous joint capsules, an absence of lymphoid hyperplasia in the white pulp of spleen and disappearance of mononuclear leukocytic infiltration when compared with the arthritic control group. This is consistent with the reduction of the proinflammatory and inflammatory cytokines and enhancement of the antiinflammatory status as a result of the treatments.

The spleen is a major organ of the body's immune system that plays a key role in prevention against invading pathogens. ${ }^{52}$ The lymphoid hyperplasia, which is a prominent feature in AA due to splenitis, ${ }^{53}$ found in the white pulps of the arthritic control group, was ameliorated clearly as a result of hesperidin and BV plus hesperidin treatments. This may be due to the effectiveness of these treatments in decreasing the count of circulating lymphocytes in blood and therefore repairing the occurring hyperplasia. However, the spleen section from arthritic rats treated with BV still showed moderate lymphoid hyperplasia in the white pulp. 
Similar arguments apply to the thymus, which is composed of peripheral cortex (primarily composed of lymphocytes or thymocytes) and central medulla (primarily composed of epithelial cells). It normally processes immature precursor T-lymphocytes into the mature immunocompetent T-cells of the medulla. ${ }^{54}$ In the current study, widening (hyperplasia) of the medulla with minimal necrobiotic changes and congestion of blood vessels and mononuclear cell infiltration in the area surrounding blood vessels were observed in thymus sections of arthritic control rats. This is in line with Ahmed et $\mathrm{al}^{43}$ and Nishino et al., ${ }^{55}$ who reported that lymphoid hyperplasia of the thymus is observed in a number of immunologically mediated disorders, including RA. The arthritic rats treated with $\mathrm{BV}$ as well as those treated with $\mathrm{BV}$ plus hesperidin exhibited improved histological section to more or less normal histological appearance. However, the thymus section from arthritic rats treated with hesperidin still depicted mild degenerated changes in lymphocytes within the medulla.

The study stated that BV and hesperidin have anti-arthritic effects in Wistar rats. However, further clinical investigations are required to assess the efficacy of $\mathrm{BV}$ and hesperidin in the treatment of RA in human beings. The study also calls for further molecular investigations to suggest the molecular mechanism(s) of action of BV and hesperidin in arthritic joints.

In conclusion, although there was no sufficient effect on the immunomodulation and antioxidant system in the arthritic group treated with BV alone, BV plus hesperidin treatment administered concurrently had a powerful therapeutic action against CFA-induced arthritis in Wistar rats. The antiarthritic effects of $\mathrm{BV}$ and hesperidin may be mediated via suppression of inflammation and oxidative stress as well as enhancement of the antioxidant defense system.

\section{Acknowledgments}

Authors are grateful to Prof. Dr. Adel M. Bakeer, Professor of Pathology, Faculty of Veterinary Medicine, Cairo University and Prof. Dr. Khalid A. El-Nesr, Professor of Pathology, Faculty of Veterinary Medicine, Beni-Suef University, Egypt for expert assistance in photographing and reading the histological slides of this work.

\section{Declaration of conflicting interests}

The authors declared no conflicts of interest with respect to the authorship and/or publication of this article.

\section{Funding}

The authors received no financial support for the research and/or authorship of this article.

\section{REFERENCES}

1. Imboden JB. The immunopathogenesis of rheumatoid arthritis. Annu Rev Pathol 2009;4:417-34.

2. Brooks PM. The burden of musculoskeletal disease--a global perspective. Clin Rheumatol 2006;25:778-81.

3. Zhang ZC, Zhang SJ, Jin B, Wu Y, Yang XF, $\mathrm{Yu} B$, et al. Ciclamilast ameliorates adjuvantinduced arthritis in a rat model. Biomed Res Int 2015;2015:786104.

4. Firestein GS. Etiology and pathogenesis of rheumatoid arthritis. In: Firestein GS, Budd RC, Gabriel SE, Mclnnes IB, O'Dell JR, editors. Kelley's textbook of rheumatology. 9th ed. Philadelphia: Elsevier Inc.; 2013. p. 1059-108.

5. Scott DL, Wolfe F, Huizinga TW. Rheumatoid arthritis. Lancet 2010;376:1094-108.

6. Surana SS, Sambath Kumar R. Anti-inflammatory and anti-arthritic activities of an isolated steroids fraction (USM) of stem bark of Machilus Macrantha nees (lauraceae). Journal of the Analgesics 2013;1:33-7.

7. Gomes A, Alam MA, Bhattacharya S, Dasgupta SC, Mukherjee S, Bhattacharya S, et al. Ethno biological usage of zoo products in rheumatoid arthritis. Indian J Exp Biol 2011;49:565-73.

8. Smolen JS, Steiner G. Therapeutic strategies for rheumatoid arthritis. Nat Rev Drug Discov 2003;2:473-88.

9. Neergheen-Bhujun VS, Munogee N, Coolen V. Antioxidant and anti-inflammatory efficacies of polyherbal formulations and elixirs traditionally used in mauritius for the treatment of rheumatoid arthritis. Journal of Herbal Medicine 2014;4:1-9.

10. Snekhalatha U, Anburajan M, Venkatraman B, Menaka M. Evaluation of complete Freund's adjuvantinduced arthritis in a Wistar rat model. Comparison of thermography and histopathology. Z Rheumatol 2013;72:375-82.

11. Gupta M, Sasmal S, Mukherjee A. Therapeutic effects of acetone extract of saraca asoca seeds on rats with adjuvant-induced arthritis via attenuating inflammatory responses. ISRN Rheumatol 2014;2014:959687.

12. Bendele A. Animal models of rheumatoid arthritis. J Musculoskelet Neuronal Interact 2001;1:377-85. 
13. Ahmed OM, EL-Abd SF, El Mahdi EA, Abdou EA. Curcumin ameliorative efficacy on type 1 diabetes mellitus coexisted with rheumatoid arthritis in Wistar rats. Merit Res J Med Med Sci 2015;3:256-70.

14. Chandrashekara S, Anilkumar T, Jamuna S. Complementary and alternative drug therapy in arthritis. J Assoc Physicians India 2002;50:225-7.

15. Patel P, Patel D, Patel N. Experimental investigation of anti-rheumatoid activity of Pleurotus sajorcaju in adjuvant-induced arthritic rats. Chinese Journal of Natural Medicines 2012;10:269-74.

16. White CJ, Nezvesky J. Bee venom therapy: a sting in the tale of rheumatoid arthritis? TSMJ 2009;10:15-7.

17. Kwon YB, Lee JD, Lee HJ, Han HJ, Mar WC, Kang $\mathrm{SK}$, et al. Bee venom injection into an acupuncture point reduces arthritis associated edema and nociceptive responses. Pain 2001;90:271-80.

18. Li R, Cai L, Xie XF, Yang F, Li J. Hesperidin suppresses adjuvant arthritis in rats by inhibiting synoviocyte activity. Phytother Res 2010;24:71-6.

19. Ernest DO, Cross MB, Ann McWilliam A. Guide to the care and use of experimental animals. 2nd ed. Canada: Canadian Council on Animal Care; 1993.

20. Whitehouse MW. Adjuvant arthritis 50 years on: The impact of the 1956 article by C. M. Pearson, 'Development of arthritis, periarthritis and periostitis in rats given adjuvants'. Inflamm Res 2007;56:133-8.

21. Balakrishnan A, Menon VP. Protective effect of hesperidin on nicotine induced toxicity in rats. Indian J Exp Biol 2007;45:194-202.

22. Visnagri A, Kandhare AD, Chakravarty S, Ghosh P, Bodhankar SL. Hesperidin, a flavanoglycone attenuates experimental diabetic neuropathy via modulation of cellular and biochemical marker to improve nerve functions. Pharm Biol 2014;52:814-28.

23. Miale JB. Laboratory medicine: Haematology. 4th ed. Saint Lucia: The C.V. Mobsy Co.; 1972.

24. Gallagher A, Hewitt G, Gibson I. Differential Giemsa staining of heterochromatic B-chromosomes in Myrmeleotettix maculatus (Thumb.) (Orthoptera: Acrididae). Chromosoma 1973;40:167-72.

25. Preuss HG, Jarrell ST, Scheckenbach R, Lieberman $\mathrm{S}$, Anderson RA. Comparative effects of chromium, vanadium and gymnema sylvestre on sugar-induced blood pressure elevations in SHR. J Am Coll Nutr 1998;17:116-23.

26. Beutler E, Duron O, Kelly BM. Improved method for the determination of blood glutathione. $\mathrm{J}$ Lab Clin Med 1963;61:882-8.

27. Marklund S, Marklund G. Involvement of the superoxide anion radical in the autoxidation of pyrogallol and a convenient assay for superoxide dismutase. Eur $\mathrm{J}$ Biochem 1974;47:469-74.

28. Matkovics B, Kotorman M, Varga IS, Hai DQ, Varga C. Oxidative stress in experimental diabetes induced by streptozotocin. Acta Physiol Hung 19971998;85:29-38.
29. Mannervik B, Guthenberg C. Glutathione transferase (human placenta). Methods Enzymol 1981;77:231-5.

30. You Z, Luo C, Zhang W, Chen Y, He J, Zhao Q, et al. Pro- and anti-inflammatory cytokines expression in rat's brain and spleen exposed to chronic mild stress: involvement in depression. Behav Brain Res 2011;225:135-41.

31. Roa M, Blane K, Zonneberg M. One Way Analysis of Variance, Version IA (C). PC-STAT, University of Georgia, Athens, USA; 1985.

32. Jiang CP, He X, Yang XL, Zhang SL, Li H, Song ZJ, et al. Anti-rheumatoid arthritic activity of flavonoids from Daphne genkwa. Phytomedicine 2014;21:830-7.

33. Forestier R, André-Vert J, Guillez P, Coudeyre E, Lefevre-Colau MM, Combe B, et al. Non-drug treatment (excluding surgery) in rheumatoid arthritis: clinical practice guidelines. Joint Bone Spine 2009;76:691-8.

34. Venkatesha SH, Rajaiah R, Berman BM, Moudgil KD. Immunomodulation of Autoimmune Arthritis by Herbal CAM. Evid Based Complement Alternat Med 2011;2011:986797.

35. Berman BM, Swyers JP, Ezzo J. The evidence for acupuncture as a treatment for rheumatologic conditions. Rheum Dis Clin North Am 2000;26:10315.

36. Eiseman JL, von Bredow J, Alvares AP. Effect of honeybee (Apis mellifera) venom on the course of adjuvant-induced arthritis and depression of drug metabolism in the rat. Biochem Pharmacol 1982;31:1139-46.

37. Geboes L, De Klerck B, Van Balen M, Kelchtermans $\mathrm{H}$, Mitera T, Boon L, et al. Freund's complete adjuvant induces arthritis in mice lacking a functional interferongamma receptor by triggering tumor necrosis factor alpha-driven osteoclastogenesis. Arthritis Rheum 2007;56:2595-607.

38. Rindfleisch JA, Muller D. Diagnosis and management of rheumatoid arthritis. Am Fam Physician 2005;72:1037-47.

39. Torsteinsdóttir I, Arvidson NG, Hällgren R, Håkansson L. Monocyte activation in rheumatoid arthritis (RA): increased integrin, Fc gamma and complement receptor expression and the effect of glucocorticoids. Clin Exp Immunol 1999;115:554-60.

40. Umar S, Kumar A, Sajad M, Zargan J, Ansari M, Ahmad S, et al. Hesperidin inhibits collagen-induced arthritis possibly through suppression of free radical load and reduction in neutrophil activation and infiltration. Rheumatol Int 2013;33:657-63.

41. Geetha T, Varalakshmi P, Latha RM. Effect of triterpenes from Crataeva nurvala stem bark on lipid peroxidation in adjuvant induced arthritis in rats. Pharmacol Res 1998;37:191-5.

42. Rasool M, Sabina EP. Evaluation of the protective potential of Spirulina fusiformis on lipid peroxidation and antioxidant status in adjuvant-induced arthritic mice. Pharmacologyonline 2008;1:300-10. 
43. Ahmed OM, Soliman HA, Mahmoud B, Gheryany RR. Ulva lactuca hydroethanolic extract suppresses experimental arthritis via its anti-inflammatory and antioxidant activities. Beni-Suef University Journal of Basic and Applied Sciences 2017 [In Press]

44. Mahajan A, Tandon VR. Antioxidants and rheumatoid arthritis. J Indian Rheumatol Assoc 2004;12:139-42.

45. Khan MM, Ishrat T, Ahmad A, Hoda MN, Khan MB, Khuwaja G, et al. Sesamin attenuates behavioral, biochemical and histological alterations induced by reversible middle cerebral artery occlusion in the rats. Chem Biol Interact 2010;183:255-63.

46. Kim W, Min S, Cho M, Youn J, Min J, Lee S, et al. The role of IL-12 in inflammatory activity of patients with rheumatoid arthritis (RA). Clin Exp Immunol 2000;119:175-81.

47. Liu YL, Lin HM, Zou R, Wu JC, Han R, Raymond LN, et al. Suppression of complete Freund's adjuvantinduced adjuvant arthritis by cobratoxin. Acta Pharmacol Sin 2009;30:219-27.

48. Germann T, Gately MK, Schoenhaut DS, Lohoff M, Mattner F, Fischer S, et al. Interleukin-12/T cell stimulating factor, a cytokine with multiple effects on T helper type 1 (Th1) but not on Th2 cells. Eur J Immunol 1993;23:1762-70.

49. Nastala CL, Edington HD, McKinney TG, Tahara
H, Nalesnik MA, Brunda MJ, et al. Recombinant IL-12 administration induces tumor regression in association with IFN-gamma production. $\mathrm{J}$ Immunol 1994;153:1697-706.

50. Lipsky PE, Davis LS, Cush JJ, Oppenheimer-Marks $\mathrm{N}$. The role of cytokines in the pathogenesis of rheumatoid arthritis. Springer Semin Immunopathol 1989;11:123-62.

51. Choy EH, Panayi GS. Cytokine pathways and joint inflammation in rheumatoid arthritis. $\mathrm{N}$ Engl $\mathrm{J}$ Med 2001;344:907-16.

52. Handy RD, Abd-El Samei HA, Bayomy MF, Mahran AM, Abdeen AM, El-Elaimy EA. Chronic diazinon exposure: pathologies of spleen, thymus, blood cells, and lymph nodes are modulated by dietary protein or lipid in the mouse. Toxicology 2002;172:13-34.

53. Issekutz AC, Sapru K. Modulation of adjuvant arthritis in the rat by 2-methoxyestradiol: an effect independent of an anti-angiogenic action. Int Immunopharmacol 2008;8:708-16.

54. Vos JG, Van Loveren H. Experimental studies on immunosuppression: how do they predict for man? Toxicology 1998;129:13-26.

55. Nishino M, Ashiku SK, Kocher ON, Thurer RL, Boiselle PM, Hatabu H. The thymus: a comprehensive review. Radiographics 2006;26:335-48. 